Universe feeding the growing public appetite for science - driven largely by the LHC and the Higgs - more people will start reading science books for fun.
Royal Society Winton Prize for Science Books shortlist 2013: Bird Sense by Tim Birkhead (Bloomsbury), The Particle at the End of the Universe by Sean Carroll (Oneworld Publications), Cells to Civilizations by Enrico Coen
(Princeton Univ. Press), Pieces of Light by Charles Fernyhough (Profile Books), The Book of Barely Imagined Beings by Caspar Henderson (Granta) and Ocean of Life by Callum Roberts (Allen Lane).

\title{
When worlds collide
}

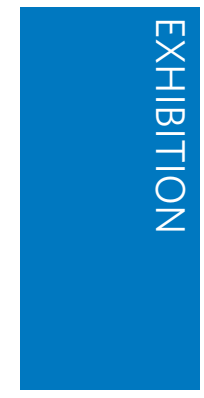

Thanks to the discovery of a Higgs-like particle, often called the 'God particle' by the media, particle physics has captured the public imagination more than any other area of physics. And CERN has become centre stage, with Professor Peter Higgs its reluctant rock star.

During the most recent set of Open Days (28-29 September 2013), 70,000 people visited CERN and many were able to see parts of the underground Large Hadron Collider itself, lying open for upgrade work at present. Now more will be able to capture the zeitgeist by visiting the Science Museum in London, which has a new exhibition, Collider: Step inside the world's greatest experiment.

Of course, it would be impossible to re-create the $27-\mathrm{km} \mathrm{LHC}$, which we learn has the same circumference as the Circle Line of the London Underground. But the exhibition does look like CERN. From the industrial look of the space decked out as the tunnel around the LHC, lined with equipment and bicycles, to the corridors and offices (pictured), it feels like a physics laboratory.

Certainly for me, I felt a bit of a jolt after sailing past all the flashy displays of the ATLAS and CMS detectors and finding myself in a corridor, peering into one of the offices. After all, during my one visit to CERN in 2002, that was pretty much all I saw: a friend's office and the library. And here was the real deal. One nostalgic particle physicist couldn't believe they'd brought over some of the actual doors!

For a 'normal' person visiting the Science Museum, there is plenty of digestible information and stunning visual displays. After all, the target audience is the curious teenager, not the jaded physicist. Near the entrance a short film captures the day they announced the big discovery on 4 July 2012. In the attempt to convey the emotions of the physicists, it comes across as slightly sentimental. I suppose the message is that
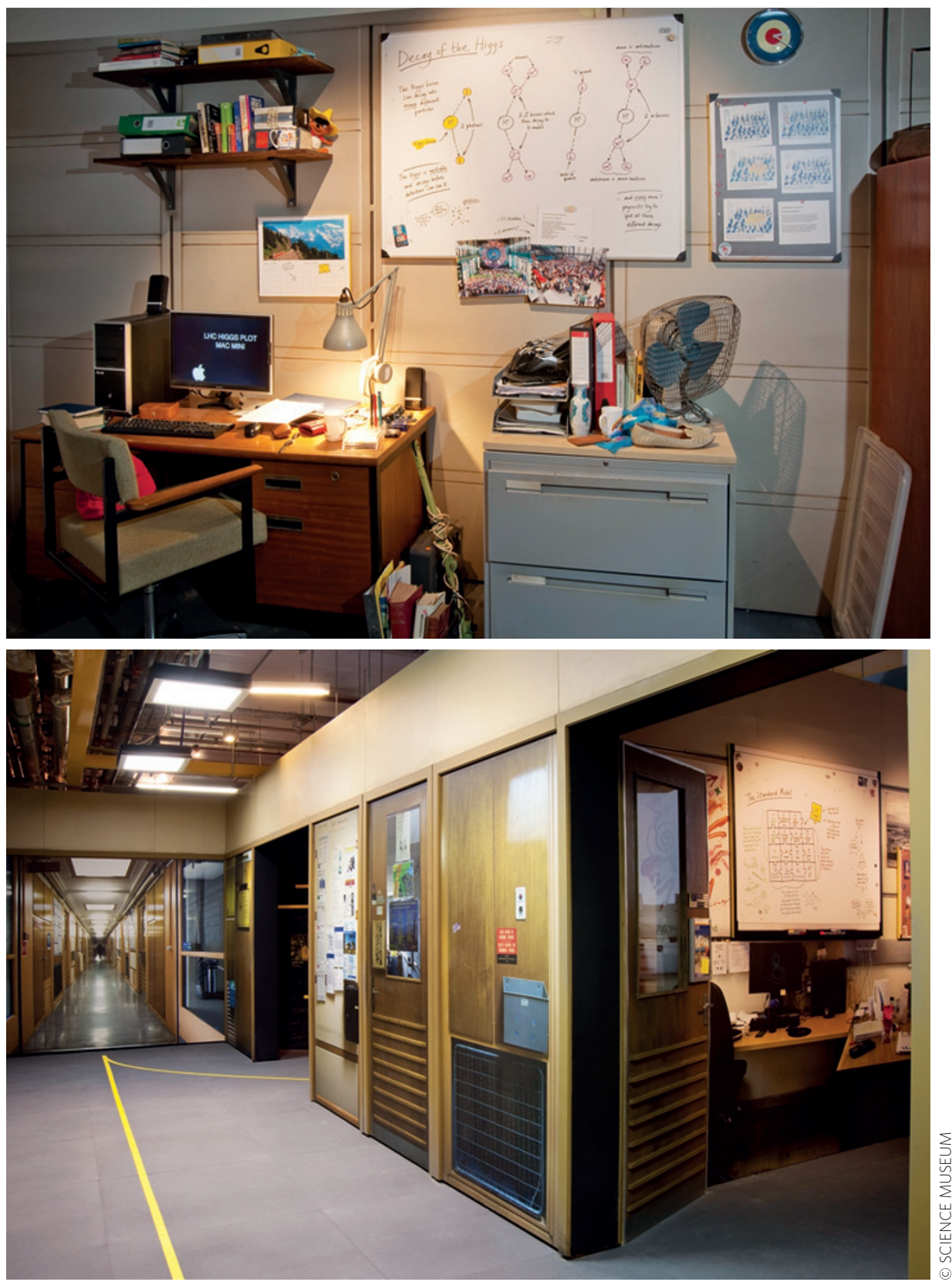

physicists are humans, which is probably a good thing.

REVIEWED BY MAY CHIAO
Collider: Step inside the world's greatest experiment runs from 13 November 2013-6 May 2014 at the Science Museum, 